\title{
HATE SPEECH Y TOLERANCIA RELIGIOSA EN EL SISTEMA HELVÉTICO DE DEMOCRACIA PARTICIPATIVA
}

DAVID MARTÍN HERRERA 
SUMARIO

1. INTRODUCCIÓN. 2. PREMISAS CONSTITUCIONALES HELVÉTICAS Y ACEPTACIÓN DEL DERECHO INTERNACIONAL. 3. DISCURSO POLÍTICO EXTREMO: «HATE SPEECH». 4. DISCURSO DE ODIO Y LEGISLACIÓN ANTIDISCRIMINACIÓN EN SUIZA. 5. CONCLUSIONES. 6. BIBLIOGRAFÍA. 7. FUENTES. 8. JURISPRUDENCIA. 
Fecha recepción: 13.11 .2013

Fecha aceptación: 5.02.2014

\title{
HATE SPEECH Y TOLERANCIA RELIGIOSA EN EL SISTEMA HELVÉTICO DE DEMOCRACIA PARTICIPATIVA
}

\author{
DAVID MARTIIN HERRERA* \\ Departamento de Derecho Político. UNED
}

"La justicia es igual a las serpientes. Sólo muerden a los que están descalzos.»

Arnulfo Romero y Galdámez, O. (Monseñor Oscar Romero)

\section{INTRODUCCIÓN}

Entre muchos de los diferentes desafíos a los que se enfrenta la sociedad globalizada, posiblemente la cuestión de la libertad de expresión y la manifestación de los diferentes credos y creencias - llegados a través de la multiculturalidad- son de las cuestiones que más debate están generando. Conocidos son los obstáculos sociales, culturales y jurídicos a los que se enfrentan los procesos de integración; siendo significativos y alarmantes, los numerosos encuentros estigmatizadores con los que tropiezan los grupos minoritarios consecuencia del desafío de la multiculturalidad.

* El presente estudio es fruto de la concesión de una estancia de investigación para el personal investigador en formación de la UNED, curso 2012/13, realizada en la Universität Luzern, Suiza. He de agradecer al Profesor Alexander Morawa y su equipo, el apoyo y comprensión ofrecidos en este período de investigación. 
La perturbadora escalada de diversos partidos ultras con discursos separatistas, cuando no violentos; el aumento de la persecución contra el inmigrante, al que frecuentemente se le asocia con el retroceso económico; y la escandalosa proliferación de sentimientos islamófobos; sin lugar a dudas, están desafiando constantemente los resentidos pilares democráticos, cuestionando la laicidad de los Estados.

A través del presente estudio vamos a tratar de reflejar algunos de los riesgos que entraña el reconocido sistema de democracia participativa helvético, donde sus conocidas iniciativas y referéndums no siempre respetan los Derechos Humanos.

Impulsados por los mecanismos del propio sistema constitucional, determinados grupos y partidos políticos pretenden subvertir el orden establecido, utilizando como bastión a la propia ciudadanía, haciendo uso de discursos y propagandas xenófobas e islamófobas en iniciativas y referéndums. Apoyándonos en estudios de diferentes instituciones y sentencias nacionales e internacionales; trataremos de dibujar los límites del discurso del odio y ratificaremos la necesidad de formar en materia de derechos humanos a las diferentes autoridades, con el fin de garantizar la libertad de expresión, al tiempo que estas, sean capaces de visualizar en concordancia con el Derecho internacional y nacional helvético, cuando lo expresable supera lo permisible.

\section{PREMISAS CONSTITUCIONALES HELVÉTICAS Y ACEPTACIÓN DEL DERECHO INTERNACIONAL}

Arranca el preámbulo de la Constitución Federal Suiza (CF) de 18 de abril de 1999, doblegando la voluntad del pueblo y de sus cantones a la Creación y en nombre de Dios omnipotente, fórmula conservada —pese a las numerosas reformas parciales - desde 1874. Así, el preámbulo que deberá inspirar el resto del articulado, atestigua por ende, una supremacía religiosa y un espíritu de solidaridad y de apertura al mundo, registrando un reconocimiento expreso de la diversidad global y precisando que la fuerza de la comunidad habrá de medirse en función del bienestar de los menos afortunados ya que «solo es libre el que utiliza su libertad» —alocución caprichosa para el estudio que nos ocupa.

Caracterizada por una mayor solidez — respecto de su antecesora- es calificada como una «Ley fundamental moderna y cercana a la ciudadanía», redactada en un lenguaje comprensivo y sistemático dividido en Títulos, Capítulos y Secciones, en detrimento de su antecesora ${ }^{1}$.

${ }^{1}$ Vid. KOLLER, H. y BIAGINNI, G. (2003), «La nueva constitución federal Suiza. Una visión general de las novedades y aspectos más destacados», UNED. Teoría y Realidad Constitucional, n. ${ }^{\circ} 10-11$, pp. 611 y ss. 
Sin ser objeto del presente estudio entrar en valoraciones materiales, interesan entre otros, los objetivos plasmados en el texto constitucional sobre la promoción de la diversidad cultural del país y de igualdad de oportunidades. Así, dentro del Título II, Capítulo I — dedicado ahora a los Derechos Fundamentales- encontramos el respeto y protección por la dignidad humana ${ }^{2}$, y un amplio artículo octavo dedicado a la «Igualdad ante la Ley». Este último establece que «todas las personas son iguales ante la ley» sin que nadie pueda ser discriminado consecuencia de su origen, raza, sexo, edad, lengua, posición social, por su modo de vida, por sus convicciones religiosas, filosóficas, políticas, o por sus incapacidades físicas, mentales o psíquicas. Aseverando que la ley debe garantizar la igualdad entre el hombre y la mujer y deberá tomar medidas para derribar desigualdades que afecten a los discapacitados.

Observamos que el legislador helvético, a priori de determinar la amplitud del principio de igualdad, hace un reconocimiento expreso a través del artículo séptimo, a la dignidad humana, que deberá ser respetada y protegida. Esta cuestión no nos resulta trivial, ya que al reconocer a la persona humana por un lado, y, por otro —en epígrafe adyacente - al hacer un llamamiento expreso a la igualdad ante la ley de todas las personas, se está reconociendo a través de la Carta Magna, que no solo los nacionales de dicho país están amparados bajo la cobertura de la ley, sino que todos y cada uno de los miembros de la comunidad humana deberán hallarse amparados en igual grado de protección dentro del ámbito de actuación de la norma fundamental.

Entre otros derechos reconocidos en el mismo Capítulo I, se reconoce la libertad de conciencia y religión, la libertad de opinión e información, la libertad de los medios de información... prohibiendo de iure la censura y la expulsión y extradición sin las debidas garantías ${ }^{3}$. Nos interesa especialmente el reconocimiento expreso que hace el pueblo suizo por medio del artículo 54.2 de su Constitución, a la contribución en la atenuación de la pobreza, así como en la promoción del «respeto por los derechos humanos, la democracia, la coexistencia pacífica de los pueblos...».

Positivados estos y otros derechos fundamentales en el texto constitucional, bien por influencia del propio Tribunal Federal — consuetudinario garante de derechos hasta ahora no positivados - o bien como gesto de apertura al derecho internacional, se creó un catálogo de derechos fundamentales que refleja también

$2 \mathrm{Al}$ respecto del vago concepto «dignidad humana», no se produjo debate legislativo alguno que determinara su alcance. Ibídem, p. 631.

3 Vid. Constitución Federal de la Confederación Suiza de 18 de abril de 1999. Artículos 15- 25. [consultado el 26 de septiembre de 2013]. Disponible en: < http://www.admin.ch/opc/it/classifiedcompilation/19995395/index.html> 
el desarrollo internacional, sin despejar la incógnita de la supremacía de la norma internacional sobre la nacional ${ }^{4}$.

Según la terminología empleada en la redacción del artículo 190CF, de forma vaga, se afirma que tanto el Tribunal Federal (TF) como las demás autoridades, estarán obligados a aplicar tanto la Ley Federal como los Tratados Internacionales, sin despejar qué norma deberá prevalecer en caso de conflicto entre lo federal y lo internacional. Tal ambigüedad debería quedar resuelta en favor del ius cogens, configurado en los artículos 193.4 y 194.2CF, como normas imperativas del Derecho Internacional inviolables.

Según Aemisegger, a partir del caso Schubert, se permitió al TF dirimir si la ley federal entraba en conflicto con el Derecho Internacional. A partir de entonces, el TF en sus decisiones ha tratado siempre de examinar que se respeten las normas internacionales, prevaleciendo únicamente el derecho nacional respecto del internacional, cuando existan claras evidencias de que la norma nacional ulterior de la internacional, fuese promovida con el conocimiento del parlamentos.

Será el TF, el que en última instancia supervise las sentencias dictadas por el Tribunal Europeo de Derechos Humanos (TEDH) que contravengan el Convenio Europeo de Derechos Humanos $(\mathrm{CEDH})^{6}$. Obligando a la autoridad administrativa competente a revisar el acto causante, dejando así las sentencias del TEDH supeditadas a su observancia y ejecución ${ }^{7}$, constatándose una vez más la supremacía nacional respecto de la internacional ${ }^{8}$.

En la lectura del recurrente fallo de 2 de marzo de 1973 (caso Schubert), se evidenció que aún reconociendo la continuidad de un Tratado internacional

${ }^{4}$ Vid. AEMISEGGER, H. (2005), «The federal judge vis- a vis the jurisdiction of the ECHR», en AA. VV., The Future Of The European Judicial System in a Comparative Perspective, Berlin, Nomos, pp. 309 y ss.

5 The Schubert judgement ruled the legal presumption that the «Swiss Legislator intended to respect all norms of international treaties being properly ratified by Switzerland. This presumption can only be disproofed [sic!], if it seems evident that the Parliament, when adopting divergent national law, deliberately intended a conflict with international law. In case of doubt, the national law must be interpreted in accordance with the international law». Ibídem, p. 310.

${ }^{6}$ Ratificado por Suiza el 28 de noviembre de 1974 [consultado el 30 de septiembre de 2013]. Disponible en: <http://www.admin.ch/opc/it/classified-compilation/19500267/index.html>

7 Recordemos que la composición del TF, emana por mandato constitucional de la elección de la Asamblea Federal, siendo elegible cualquier persona con derecho de voto en materia federal. Vid. Artículo 169CF y Artículo 5, Legge sul Tribunale Federale (LTF) del 17 giugno 2005, [consultado el 26 de septiembre de 2013]. Disponible en: <http://www.admin.ch/opc/it/classifiedcompilation/20010204/index.html>

${ }^{8}$ Ibídem, pp. 312 y ss. 
allende de la norma nacional — más actual— se confirió especial relevancia al Derecho nacional respecto del internacional ${ }^{9}$.

\section{1. ¿Qué ocurre cuando el pueblo requiere una norma o ejecuta un acto contra el ius cogens?}

Según el artículo 36CF, cualquier injerencia en los derechos fundamentales debe estar apoyada en una norma legal y debe ser justificada en beneficio del interés público o por la necesidad de proteger los derechos de terceros.

Como baluarte de la soberanía popular que «ensalza el régimen político suizo» ${ }^{10}$, la carta magna (artículos 139.3 y 139a) supedita a la Asamblea federal (AF), en detrimento del TF, la declaración de nulidad total o parcial de las iniciativas populares que no respeten las disposiciones imperativas del derecho internacional o que violen el principio de unidad de forma ${ }^{11}$. Sin embargo, la praxis confirma que esto no siempre sobreviene; por un lado, por la supresión de las iniciativas populares genéricas y la consecuente derogación del artículo 139. ${ }^{a}$ (desde el 19 de diciembre de 2008) ${ }^{12}$ y por otro, tal y como apunta Fleiner, debido a la vaguedad con la que se formuló el concepto «respeto», referido al derecho internacional, que no despejó la supremacía final de este último ${ }^{13}$.

La respuesta nos la proporciona la jurisprudencia internacional, así entre otros, la Corte Interamericana de Derechos Humanos dejó claro que teniendo en

9 Essendo pacifico che l'Assamblea federale era cosciente dell'eventuale rilevanza sotto il profilo del diritto internazionale della reglamentazione de essa posta in essere, non incombe al Tribunae federale d'analizare tale aspetto. Poichè, per il motivi illustrati, la valità del DF 1961/1970 nei confronti dei cittadini austriai domiciliati all'estero non e pregiudicata dal Trattato del 1875, il Tribunale federale è tenuto ad applicare tale decreto federale ai sensi dell'art. 113 cpv. 3 CF. Vid. Sentencia del Tribunal Federal BGE 99 IB 39 [consultado el 3 de octubre de 2013]. Disponible en: <http://www.bger.ch/it/index/juridiction/jurisdiction-inherit-template/ jurisdiction-recht/jurisdiction-recht-leitentscheide1954.htm>

${ }^{10}$ Vid. RUIZ VIEYTEZ, J. (2013), «Democracia Directa y Religión: Problemas Derivados de la Decisión Suiza de Prohibir los Minaretes», Revista de Derecho Político, núm. 87, pp. 262-263.

11 Vid. KOLLER, H. y BIAGINNI, G. (2003), «La nueva constitución federal Suiza. Una visión general de las novedades y aspectos más destacados», UNED. Teoría y Realidad Constitucional, n. ${ }^{\circ} 10-11$, p. 624.

12 [consultado el 3 de octubre de 2013]. Disponible en: <http://www.admin.ch/opc/it/ official-compilation/2009/6409.pdf>

13 «Thus, although the state is bound to act in good faith according to articule 5(3) of the Constitution, it is not entirely clear whether this provision may be considered as the constitution basic for the supremacy of international law over national law. Vid. FLEINER, T., MISIC, A., TÖPPERWIEN, N. (2005), Swiss Constitutional Law, Berna, Kluwer Law International, p. 44. 
cuenta la trayectoria del Derecho Internacional de los Derechos Humanos (al que la Confederación Helvética brinda especial relevancia entre otros en el artículo 54.2CF), tanto el principio de no discriminación como el del acceso a la protección efectiva e igualitaria ante la ley, deben de ser tratados como normas de derecho internacional imperativo no oponibles a otras normas de derecho internacional, cuan menos nacional, dando lugar a un cuerpo jurídico internacional de ius cogens, integrador de un orden jurídico internacional superlativo al resto de normas jurídicas ${ }^{14}$.

Asevera Varón, que son los propios Estados lo que deben de reconocer «que normas son ius cogens» ${ }^{15}$. Dicha tesis contradice con lo preceptuado por el artículo 53 de la Convención de Viena sobre el derecho de los tratados, el cual declara nulos, aquellos tratados que colisionen con normas imperativas de derecho internacional; resultando así impracticable, tratar de eludir obligaciones erga omnes del derecho internacional por la vía del referéndum popular.

\section{DISCURSO POLÍTICO EXTREMO: «HATE SPEECH»}

Resulta indiscutible que uno de los pilares en los que se asienta cualquier sistema democrático reside en el derecho a expresar libremente pensamientos, creencias e ideologías, a través de cualquier medio. Este es un Derecho universalmente reconocido y configurado entre otros, mediante los artículos 16, 17 y $34 \mathrm{CF}$.

Pero, ¿qué ocurre cuando haciendo uso de este derecho fundamental se lesionan otros derechos? En tales supuestos, el legislador helvético ha establecido la observancia de los límites del artículo 35CF, entendiéndose que el propio derecho a la libertad de expresión y opinión no puede ser infinito. Dicha limitación deberá quedar garantizada y justificada en beneficio del interés público o para asegurar la protección de derechos fundamentales de terceros, tal y como establece el artículo 36.2CF.

Según el Pacto Internacional de Derechos Civiles y Políticos (PIDCP) ${ }^{16}$, la libertad de expresión es un derecho individual por el que toda persona puede

14 Vid. Corte Interamericana de Derechos Humanos, «Opinión Consultiva OC-18/03 de 17 de septiembre de 2003, Solicitada por los Estados Unidos Mexicanos, P. 93 [consultado el 6 de abril de 2012]. Disponible en: <http://www.corteidh.or.cr/docs/opiniones/seriea_18_esp.pdf>

15 Vid, VARÓN MEJÍA, A. (2010), «Orden público internacional y normas ius cogens: una perspectiva desde la comisión de derecho internacional y la convebnción de Viena de 1969», Diálogos de saberes: investigaciones y ciencias sociales, núm. 32, p 228.

16 En vigor en Suiza desde el 18 de septiembre de 1992 [consultado el 3 de octubre de 2013]. Disponible en:

<http://www.admin.ch/opc/it/classified-compilation/19660262/index.html> 
«buscar, recibir y difundir informaciones e ideas de toda índole, sin consideración de fronteras», entrañando su ejercicio, deberes y responsabilidades fijados por la ley para asegurar el respeto de los derechos de los demás, la seguridad y el orden público ${ }^{17}$. Dicha seguridad y orden se enfatizan en la restricción a toda propaganda en favor de la guerra y en la interdicción de toda «apología del odio nacional, racial o religioso que constituya incitación a la discriminación, la hostilidad o la violencia» ${ }^{18}$.

Los razonamientos en materia de libertad de expresión del Convenio Internacional sobre la Eliminación de todas las Formas de Discriminación Racial $(\mathrm{CIEDR})^{19}$ llegan aún más lejos, restringiendo toda difusión de ideas basadas en la superioridad y en el odio racial y toda incitación a la discriminación racial; declarando ilegales todas aquellas organizaciones y sus actividades, así como toda aquella actividad de propaganda que promueva e incite la discriminación racial $^{20}$.

Pese a lo acertado de aquellos planteamientos, su fondo resultó sumamente errado al dejar en manos del Derecho nacional la determinación de los límites del discurso del odio y su restricción.

\subsection{Restringir o desatar la libertad de expresión. Casos e interpretaciones}

Para poder comprender la disparidad de opiniones en la interpretación del discurso del odio a través del derecho nacional, resulta de obligada lectura reseñar aquel legendario «clear and present danger» formulado en voto disidente por el Juez Holmes en el caso Schenck vs. United States ${ }^{21}$.

17 De forma vaga se limita en el mismo epígrafe, el ejercicio de la libertad de expresión en cuestiones tan etéreas como la salud o moral pública. Vid. Asamblea General de Naciones Unidas, Resolución 2200 A (XXI), de 16 de diciembre de 1966, «Pacto Internacional de Derechos Civiles y Políticos», Artículo 19 [consultado el 6 de abril de 2013]. Disponible en:<http://www2.ohchr. org/spanish/law/ccpr.htm>

${ }^{18}$ Ibídem, Artículo 20.

19 En vigor en Suiza desde el 29 de diciembre de 1994 [consultado el 3 de octubre de 2013]. Disponible en: <http://www.admin.ch/opc/it/classified-compilation/19650268/index.html>

20 Vid. Asamblea General de Naciones Unidas, Resolución 2106 A (XX), de 21 de diciembre de 1965, «Convención Internacional sobre la Eliminación de todas las Formas de Discriminación Racial», Artículo, 4 [consultado el 6 de abril de 2013]. Disponible en: $<$ http://www2.ohchr.org/ spanish/law/cerd.htm>

21 «The most stringent protection of free speech would not protect a man in falsely shouting fire in a theatre and causing a panic. The question in every case is whether the words used are used in such circumstances and are of such nature as to create a clear and present danger that they will bring about the substantive evils that Congress as right to prevent. It is a question to 
Medio siglo transcurrió desde aquel revolucionario voto, por el que se discrepaba acerca de la persecución y castigo del disidente (que no suponía un evidente peligro), hasta el boceto expuesto por el Juez Douglas en el caso Brandenburg vs. Ohio ${ }^{22}$, que trató de distinguir entre «ideas y actos» ${ }^{23}$ configurados por la línea entre lo permisible — no sujeto a control—y lo restringible, sujeto a reglamentaciones.

Aquel punto de inflexión entre la persecución del disidente y la manumisión de la libertad de expresión —incluso a través de la reivindicación del uso de la fuerza o la violación de las leyes- supuso un cambio de rumbo en el que se dejó de dirimir respecto a condenas de pensamientos abstractos, omitiendo erradamente enseñanzas capaces de suscitar a la violencia ${ }^{24}$.

La jurisprudencia estadounidense confirmó que la libertad de expresión y de prensa no permite que un Estado prohíba o proscriba la reivindicación del uso de la fuerza ni la violación de las leyes, salvo en los casos en que dicha reivindicación tenga por objeto incitar o producir actos ilícitos inminentes ${ }^{25}$. A priori, tales afirmaciones podrían suponer un avalado reconocimiento al significado de la libertad de expresión, y para autores como Fiss fue «una de las bendiciones de nuestra libertad ${ }^{26}$. Sin embargo, acreditar en pro de la libertad de expresión aseveraciones como «bury the niggers», ni resultan ser motivo de elogio, ni cuan menos embragan con el Derecho Internacional de los Derechos Humanos, por

proximity and degree». Vid. HOLMES, O. W., Schenck vs. United States 249 US. 47, 1919, Voto Disidente.

22 «The line between what is permissible and not subject to control and what may be made impermissible and subject to regulation is the line between ideas and overt acts. The example usually given by those who would punish speech is the case of one who falsely shouts fire in a crowded theatre». Vid. DOUGLAS, W. O., Brandenburg vs. Ohio, 395 U. S. 444, Voto Concurrente, 1969.

${ }^{23}$ Ibídem.

${ }^{24}$ En alusión al caso Herndon vs. Lowry, 301 U. S. 242, 259 (1937) y Bond v. Floyd, 385 U. S. 116, 134 (1966), la Corte Suprema aseveró, que la mera enseñanza de la necesidad moral de recurrir a la fuerza no es lo mismo que preparar un grupo para la acción violenta... — disentimos en la distinción entre el pensamiento abstracto y la enseñanza del mismo, si bien, ambos son legítimos, la enseñanza sí que puede desencadenar acciones no deseadas, mientras que el pensamiento, es algo inherente al sujeto- «the mere abstract teaching... of the moral propriety or even moral necessity for a resort to force and violence, is not the same as preparing a group for violent action and steeling it to such action.» Vid. Brandenburg vs. Ohio, 395 U. S. 444, 1969.

${ }^{25}$ Ibídem, Per Curiam.

26 Vid. FISS, O. (2011), «Libertad de expresión y estructura social» en AA. VV., Libertad de expresión: debates, alcances y nueva agenda, Quito, Oficina del Alto Comisionado de las Naciones Unidas para los Derechos Humanos, p. 68. 
su menosprecio a un sector de la sociedad y por su palpable «peligro real e inminente» de que tales declaraciones sean la antesala para la perpetración de agresiones, denegaciones de servicios o de daños a las propiedades de una determinada facción de la población.

\subsection{Determinando los limites de lo expresable. Un apunte a la CADH}

Para que podamos apreciar cuándo un discurso roza el límite de lo reivindicable, nos resulta imprescindible conocer la clave en la que se hallarían los límites entre la incitación y su probabilidad de éxito, resultándonos una ecuación ideal de imposible solución temprana. En este aspecto y en contra de la apreciación del Instituto Interamericano de Derechos Humanos que apunta que los términos de la Convención Americana de Derechos Humanos (CADH) fueron más acordes con la jurisprudencia estadounidense ${ }^{27}$, consideramos que aquella, cuidó su redacción al respecto de los límites de la libertad de expresión — no fijados explícitamente en la jurisprudencia estadounidense. En contra de lo sostenido por autores como Paúl, que aseveran que el enfoque de la $\mathrm{CADH}$ al estar inspirado en Brandenburg resultó más liberal que el del CEDH o del PIDCP en materia de libertad de expresión ${ }^{28}$; observamos de su propia lectura una consonancia con lo establecido por el PIDCP y el CIEDR distanciándose del CEDH. Pero, veámoslo.

De la misma época del CIEDR, el CADH establece en un amplio artículo 13 el derecho a la libertad de pensamiento y expresión sin censura previa, con responsabilidades ulteriores; asegurando el respeto de los derechos y reputación de terceros, la seguridad nacional y la (abstracta) salud y moral pública.

De forma revolucionaria la CADH insertó la posibilidad de censurar por cuestiones de protección de la infancia y adolescencia —en relación a la pornografía infantil - y delimitó en su epígrafe quinto, los tipos de propaganda a restringir mediante ley: «toda propaganda en favor de la guerra y toda apología del odio nacional, racial o religioso que constituyan incitaciones a la violencia o cualquier otra acción ilegal similar contra cualquier persona o grupo de personas,

27 En opinión de investigadores de este Instituto, «el enfoque actual de Estados Unidos específicamente requiere la intención de incitar a una actividad ilegal y la probabilidad de éxito lo cual concuerda más con los términos de la Convención Americana, en oposición a otros instrumentos internacionales de derechos humanos». Vid. SOLANO, M. (2003), Libertad de expresión en las Américas. Los cinco primeros informes de la Relatoría para la Libertad de Expresión, Instituto Interamericano de Derechos Humanos, San José, pp. 220 y ss.

${ }^{28}$ Vid. PAÚl DÍAZ, A. (2011), «La penalización de la incitación al odio a la luz de la jurisprudencia comparada», Revista Chilena de Derecho, N. ${ }^{\circ}$ 2, p. 579. 
por ningún motivo, inclusive los de raza, color, religión, idioma u origen nacional» ${ }^{29}$.

Por su concreción, no podemos considerar que el artículo $13 \mathrm{CADH}$, sea ni próximo a la jurisprudencia del caso Brandenburg ni discriminatorio - como apuntaba dicha sentencia - con aquellas acciones que amparadas bajo el derecho de la libertad de expresión, pretenden sobrepasar los límites establecidos por esta norma. Por lo pragmático de su redacción, consideramos que debe ser un referente en la lucha contra la discriminación, el discurso del odio y su último estadio: los delitos de odio.

\subsection{Entonces, ¿cuándo la libertad de expresión sobrepasa sus limites?}

Regresando al continente europeo y comparándolo con otros convenios internacionales, la redacción dada por el legislador europeo a la libertad de expresión en el artículo 10 del $\mathrm{CEDH}$ no fue lo acertada y precisa que debiera al ser un Convenio más veterano que los anunciados anteriormente. La vaga delimitación del ejercicio de la libertad de expresión a los supuestos en los que se pudiera comprometer: «la seguridad nacional, la integridad territorial o la seguridad pública, la defensa del orden y la prevención del delito» ${ }^{30}$, así como la protección de la salud, de la moral y la reputación; ha generado acalorados debates en los escasos pronunciamientos del TEDH.

En comparación con la CADH que requiere restringir el discurso del odio cuando se incite a la violencia, el $\mathrm{CEDH}$, «no requiere explícitamente a los estados prohibir la incitación al odio, pero permite aquellas restricciones a la libertad de expresión, que sean necesarias en una sociedad democrática» ${ }^{31}$.

De la jurisprudencia del TEDH se desprende que el ejercicio de la libertad de expresión es un derecho sumamente reconocido que da cobertura a la formación de ideas e informaciones inofensivas e indiferentes, admitiendo como válidas aquellas otras que «molestan, chocan o inquietan, pues así lo requieren el pluralismo, la tolerancia y el espíritu de apertura sin los cuales no hay sociedad

29 Vid. Secretaria General OEA. Convención Americana sobre Derechos Humanos. Pacto de San José de Costa Rica. Serie sobre Tratados OEA No 36 — Registro ONU 27/08/1979 No 17955, Costa Rica, 1969, Artículo, 13.

30 Vid. Consejo de Europa. (1950), Convenio Europeo para la Protección de los Derechos Humanos y de las Libertades Fundamentales, Roma, Artículo, 10.

31 Vid. BERTONI, E. y RIVERA, J. (2012), «The American Convention on Human Rights. Regulation of Hate Speech and Similar Expression», en, HERZ. M. y MOLNAR. P., The Content and Context of Hate Speech. Rethinking Regulation and Responses, New York, Cambridge University Press, pp. 503 y ss. 
democrática» ${ }^{32}$. Línea establecida por el Tribunal Constitucional Español (TC) admitiendo que la libertad de expresión comprende la libertad de crítica, incluyendo los supuestos en que se «pueda molestar, inquietar o disgustar a quien se dirige, pues así lo requieren el pluralismo, la tolerancia y el espíritu de apertura, sin los cuales no existe sociedad democrática» ${ }^{33}$. Jurisprudencia que se desmarca de los modelos de «democracia militante» adoptados por la Constitución alema$\mathrm{na}^{34}$ y como apunta Ruiz, en forma participativa en Suiza.

Sin embargo, la libertad de expresión no resulta un baluarte con el que se pueda llegar tan lejos como alcance el pensamiento. Es por ello, por lo que su ejercicio no ha de estar exento de deberes y responsabilidades, sin que pueda llegar a ser considerado un derecho absoluto por medio del cual se puedan difundir mensajes ofensivos, ultrajantes y que invoquen al desprecio de grupos determinados por especiales características. Por tanto cualquier manifestación racista, vejatoria, vilipendiadora, humillante o que incite a ejecutar acciones en contra del Derecho internacional de los derechos humanos, deben de quedar fuera del ámbito de protección del Derecho a la libertad de expresión. «El odio y el desprecio a todo un pueblo o a una etnia son incompatibles con el respeto a la dignidad humana» ${ }^{35}$.

Refiriéndose al discurso religioso, Guiora defiende que los gobernantes con el fin de prevenir ataques violentos, deben de intervenir tan pronto como un orador inicia su discurso incitador ${ }^{36}$. Pero recordemos que el discurso del odio puede ser bilateral y para ello debemos de contar con unas estructuras capaces de detectarlo precozmente, dado que en caso contrario, ¿quién puede intervenir cuando son las estructuras del poder las que incitan al odio mediante el discurso o la propaganda? Alguna respuesta podría interpretarse del conocido caso Féret vs. Bélgica. A través del mismo el TEDH puso en relieve el valor del derecho a la libertad de expresión, considerado tradicionalmente en su propia jurisprudencia como «uno de los pilares esenciales en cualquier sociedad democrática» ${ }^{37}$. Siendo para el juez europeo un valor especialmente meritorio cuando es ejercido

32 Vid. Sentencia del Tribunal Europeo de Derechos Humanos de 23 de septiembre de 1988 (Lediheux), Sentencia del Tribunal Europeo de Derechos Humanos de 23 de abril de 1992 (Castells), Sentencia del Tribunal Europeo de Derechos Humanos de 24 de febrero de 1997 (Haes y Gijsels).

33 Vid. Sentencia del Tribunal Constitucional 174/2006, de 5 de junio, FJ 4.

34 Vid. Ley Fundamental para la República Federal Alemana, Artículo 21.2.

35 Vid. Sentencia del Tribunal Constitucional 214/1991, de 11 de noviembre, FJ 8.

36 Vid. GUIORA, A. N. (2009), Freedom from religion. Rights and national security, New York, Oxford University Press, p. 45.

37 Vid. Sentencia del Tribunal Europeo de Derechos Humanos de 20 de mayo de 1999, Rekvényi vs. Hungary, N. 25390/94, Ep. 42. 
por un representante elegido por el pueblo en representación de su electorado, resultando necesario que cualquier injerencia en la libertad de expresión precise de «un control más estricto» ${ }^{38}$. Es por ello, por lo que el Tribunal europeo rechazó en aquel fallo que hubiese sido vulnerado el derecho a la libertad de expresión del demandante al haber sido necesario restringirlo, debido a la urgente necesidad social de proteger el orden público y los derechos de los inmigrantes, convertidos en el objetivo del discurso de odio del señor Féret ${ }^{39}$.

Aquella urgente necesidad de proteger a un sector de la población amenazado a consecuencia del discurso del odio, se afianza — pese a la deficiente redacción del convenio- en el caso Vejdeland and others vs. Sweden. En dicho caso, el TEDH reconoció que la propaganda emitida en una escuela secundaria por varios escolares en contra de personas homosexuales a los que se les culpó de ser los causantes del SIDA y el VIH, disponía contenidos inaceptables ${ }^{40}$. Sin embargo, el mismo Tribunal no se atrevió a pronunciarse en relación al concepto del discurso del odio pese a haber sido requerido por las terceras partes implicadas en el proceso ${ }^{41}$. Positivamente dicho caso constató que la incitación al odio, no necesariamente implica una llamada a la violencia, dado que ataques cometidos a través de insultos con capacidad de ridiculizar o calumniar a grupos de población, son motivo suficiente para que las autoridades combatan el discurso racista ${ }^{42}$.

El desvalor del TEDH, sin dudas ha sido una reciente oportunidad perdida en la consolidación del discurso del odio, reclamada en votos concurrentes por los Jueces Yudkivska y Villiger ${ }^{43}$, que apelaron a la Resolución del Consejo de Ministros del Consejo de Europa, a través de la que se define «hate speech», como todas las formas de expresión mediante las que se «difunda, incite, promueva o justifique el odio racial, la xenofobia, antisemitismo (consideramos más correcto el odio por cuestiones religiosas) y otras formas de odio basadas en la intolerancia, incluyendo: intolerancia expresada a través de nacionalismos agresivos y

38 Vid. Sentencia del Tribunal Europeo de Derechos Humanos de 16 de Julio de 2009, Ferét vs. Belgium, N. ${ }^{\circ} 15615 / 07$, Ep. 65 y 77.

39 «The language used by the applicant with clear incentives to discrimination and racial hatred, which can not be camouflaged by the electoral process». Ibídem, Ep. 78.

40 Vid. Sentencia del Tribunal Europeo de Derechos Humanos de 9 de febrero de 2012, Vejdeland and others vs. Sweden, no. 1813/07, Ep. 8.

41 Según Interrights y la International Commission of Jurists, el TEDH no había tenido oportunidad de desarrollar una jurisprudencia en relación al discurso del odio, no proporcionó una definición que brindaba la oportunidad de pronunciarse; dado que la discriminación basada en la orientación sexual resultaba tan grave como la basada en cuestiones de raza, origen, color, sexo. Ibídem, Eps, 42- 44.

42 Ibídem, Ep. 55.

${ }^{43}$ Ibídem, Voto concurrente, p. 21. 
etnocentrismo, discriminación y hostilidad contra minorías, migrantes y las personas de origen inmigrante» ${ }^{44}$.

Autores como West —refiriéndose al discurso racista- apuntan que la incitación al odio difiere del discurso discriminatorio principalmente en que este último busca difundir una imagen negativa de su objetivo, mientras que el discurso de odio pretende causar un daño psicológico o despertar la hostilidad hacia el grupo a quien se dirige el mensaje $e^{45}$. La cuestión última será discernir cuándo dicho discurso sobrepasa los límites ${ }^{46}$, extremo difícil de atacar mientras no se establezcan unas pautas mínimas que resguarden los derechos de las minorías. En todo caso, cualquier restricción a la libertad de expresión deberá de estar siempre justificada en la protección de los intereses sociales e individuales, y nunca para proteger instituciones ni creencias tal y como establece la Relatoría de las Naciones Unidas para la libertad de opinión y expresión ${ }^{47}$.

\section{DISCURSO DE ODIO Y LEGISLACIÓN ANTIDISCRIMINACIÓN EN SUIZA}

De la lectura de los últimos informes emitidos sobre Suiza por la Comisión Europea contra el Racismo y la Intolerancia (ECRI), se viene reiterando a las autoridades helvéticas prestar especial atención a las diferentes manifestaciones racistas y xenófobas en política. Identifica la ECRI un cambio en el discurso político a través del incremento de representación parlamentaria del partido político Union démocratique du centre/ Schweizerische Volkspartei (UDC/SVP), conocido por sus programas, campañas, y propaganda racistas y xenófobas. A través de las mismas, se acusa al inmigrante de abusar del sistema social, de falsear los procedimientos de asilo, de ser — los inmigrantes procedentes de los

${ }^{44}$ Vid. Council of Europe. Committee of Ministers, Recommendation No. R. (97) 20 of the Committee of Ministers to Members States on 'Hate Speech'», 30 de octubre de 1997, 607th meeting.

45 Vid. WEST. C. (2012), «Words That Silence? Freedom of Expression and Racist Hate Speech» en MAITRA. I y McGOWAN. M., Oxford University Press, p. 232.

46 Para tratar de profundizar sobre lo que consideramos discurso extra-limitado. Vid. MARTÍN HERRERA, D. (2012), «Constitucionalidad del Discurso de Odio. Cuando el 'Hate Speech' se convierte en 'Hate Crime’» (2013). Asociación de Constitucionalistas de España, XI Congreso [consultado el 2 de marzo de 2013]. Disponible en: <http://www.acoes.es/congresoXI/pdf/ M2Com-DavidMartinHerrera.pdf>

47 Vid. Relator Especial de las Naciones Unidas para la Libertad de Opinión y Expresión, Declaración conjunta sobre difamación de religiones sobre legislación antiterrorista y anti-extremista» (2008). Campaña Global para la libertad de expresión, Atenas. 
Balcanes - los principales causantes del aumento de la delincuencia, de ser narcotraficantes - los negros - y de ser terroristas y fundamentalistas - los musulmanes-, siendo posible apreciar este tipo de discursos incluso a través de los propios medios de comunicación ${ }^{48}$.

De resultar ciertas las prácticas políticas denunciadas por la ECRI, colisionarían directamente con lo establecido en el artículo 261bis del Código Penal. El mismo, castiga a los que «inciten públicamente al odio o la discriminación contra una persona o grupo de personas por su raza, etnia o religión $[\ldots .$.$] a los que pro-$ paguen públicamente una ideología destinada a desacreditar o calumniar sistemáticamente $[\ldots]$ a los que, con el mismo objetivo organizan o fomentan acciones de propaganda $[\ldots]$ a los que públicamente, mediante palabras, escritos, imágenes, gestos $[\ldots]$ desacreditan o discriminan una persona o grupo de personas por su raza, etnia o religión o por las mismas razones, niegan, minimizan o tratan de justificar el genocidio u otros crímenes contra la humanidad» ${ }^{49}$. En semejantes términos se pronuncia el Código Penal Militar ${ }^{50}$, habiendo sido introducidos ambos artículos en sendos códigos mediante Ley Federal de junio de 1993.

Después de más de una década, la estrategia del Consejo Federal (BR) en materia de extremismo en política, se creía nítida cuando apuntaba que: «en Suiza no se puede tolerar violencia, odio y xenofobia; el extremismo de derechas se debe combatir de forma preventiva y de forma represiva, mediante coordinación e información ${ }^{51}$. Para ello se encargó la creación de un grupo especializado $(\mathrm{REX})^{52}$, bajo el mando de la Policía federal. El mismo, elaboró un informe por el que se recomendaba «condenar todas formas de extremismo orientados a la violencia y no únicamente aquellos violentos» ${ }^{53}$, entre otros, se requirió la creación de nuevos tipos penales, dado que, con la redacción del artículo 261 bis no resultaba posible interferir en cuestiones políticas, máxime

48 Vid. European Commission Against Racism and Intolerance, ECRI report on Switzerland (fourth monitoring cycle), CRI (2009)32, Ep. 88-102.

49 Codice Penale Svizzero del 21 dicembre 1937 (Stato 1. ${ }^{\circ}$ luglio 2013), Art. 261bis [consultado el de octubre de 2013]. Disponible en: <http://www.admin.ch/opc/it/classified-compilation/ 19370083/index.html>

${ }^{50}$ Codice Penale Militare del 13 giugno 1927 (Stato 1. ${ }^{\circ}$ gennagio 2013), Art. 171c [consultado el 3 de octubre de 2013]. Disponible en: <http://www.admin.ch/opc/it/classified-compilation/ 19270018/index.html>

51 Vid. Legge federale concernente misure contro il razzismo, la tifoseria violencia e la propaganda violenta. Spiegazione, (2003), p. 4. [consultado el 3 de octubre de 2013]. Disponible en: $<$ http://www.fedpol.admin.ch/content/dam/data/kriminalitaet/extremismus_rassismus/ 12rapporto_20razzismo-i.pdf>

52 Ibídem, p. 5.

53 Ibídem, p. 5. 
cuando el BR no presentaba interés alguno de crear ninguna «ley mordaza» con efectos de silenciamiento ${ }^{54}$.

De forma conexa el Departamento Federal de Policía y Justicia solicitó en 2009 la modificación del Código Penal, dado que en la práctica policial — refiriéndose al uso de simbología racista — resultaba imposible probar cuando un imputado pretendía realmente influenciar en el público al ser la publicidad del acto uno de los elementos esenciales de la prueba ${ }^{55}$. Para ello, proponían un nuevo artículo 261 ter, por el que se detallara el principio de certeza «Bestimmtheitsgebot» o nulla poena sine lege certa, con el fin de simplificar la aplicación de la norma y no incrementar el riesgo de que la ciudadanía, auto estableciera límites mayores por miedo a ser sancionados ${ }^{56}$.

Coincidiendo en la necesidad de legislar de forma inteligible, consideramos que tanto la legislación nacional y por supuesto la internacional, brindan a los Cuerpos Policiales y la Fiscalía una estructura suficiente para poder atajar el discurso del odio, existiendo voluntad previa y conocimientos suficientes para percibirlo. Es por ello, por lo que entre otras recomendaciones, la ECRI requiere impartir formación en materia de derechos humanos a los diferentes cuerpos policiales, jueces, fiscales y profesionales implicados en la lucha contra el racismo y la discriminación; siguiendo las recomendaciones de política general n. ${ }^{\circ} 11^{57}$.

Sin embargo, hasta ahora únicamente se ha impartido formación en materia de interculturalidad —en colaboración con la ONG LICRA y la Ombudsfrau de Zúrich - a varios cuerpos policiales, omitiéndose a jueces, fiscales y profesionales, sin quedar constatada a día de hoy modificaciones legales alguna en la materia ${ }^{58}$.

54 «La caratteristica della pubblicità di cui all'articolo 261bis CP non deve essere tocata soprattutto per motivi politici. Questo nella consapevolezza che l'assicurazione del Consiglio federale secondo cui non era prevista nessuna «legge museruola» $[. .$.$] . I limiti posti dalla libertà$ d'espressione non possono essere superati. Ibídem, p. 16.

55 Vid. Dipartimento Federale di Giustizia e Polizia. (2009). «Rapporto e avamprogetto di modifica del Codice penale svizzero e del Codice penale militare concernente i simboli razzisti», pp. 17 y ss.

56 «La legge debe essere formulata in modo così preciso da consentire al cittadino di potersi comportare senza violarla e di riconoscere le conseguenze di un determinato comportamento». Ibídem, p. 14.

57 Vid. Council of Europe. European Commission Against Racism and Intolerance. (2007). «ECRI. General Policy Recommendation N. ${ }^{\circ} 1$ on Combating Racism and Racial Discrimination on Policing», CRI 39. [consultado el 15 de octubre de 2013]. Disponible en: <http://www.coe.int/t/dlapil/codexter/Source/ECRI_Recommendation_11_2007_EN.pdf>

${ }_{58}$ ECRI, «already expressed regret that the intercultural competence training initiatives only concerned some of Switzerland's police forces». Vid. Council of Europe. European Commission Against Racism and Intolerance (2012). «ECRI. Conclusions on the implementation of the recom- 
A las propuestas de la ECRI y del grupo REX, se le anudan las de la Comisión Federal contra el Racismo (FCR) —establecida por el BR - que en su último informe solicitaba al BR, dejar de interpretar la libertad de expresión de forma amplia en el ámbito político, dado que la protección contra la discriminación resultaba indiferente en los procesos de democracia directa, y la propaganda racista no era cuestionada ${ }^{59}$. Por ello recomendaba dejar de tolerar discursos racistas, así como abandonar las reservas establecidas al CIEDR ${ }^{60}$.

Reservas establecidas temerariamente al PIDCP, en relación a la libertad de circulación del artículo 12.1; a la prohibición de la propaganda del mencionado artículo 20; al sufragio universal libre, directo y secreto que garantice la libertad de expresión del electorado, establecida en el artículo 25.b; y a la limitación del principio de igualdad ante la ley del artículo $26^{61}$.

Pese a las irreflexivas reservas expuestas, la Confederación helvética no estableció mayores reservas al CEDH que las conocidas a los artículos 5 y 6 , y que consecuencia del caso Belilos ${ }^{62}$, acabó siendo promovida por el BR su retirada ${ }^{63}$.

Es por ello por lo que consideramos que la mínima jurisprudencia europea en relación al discurso de odio, resultaría presupuesto suficiente para atajar el fenómeno siempre y cuando existiera voluntad institucional para hacerlo. Sin embargo, como vamos a ver, dicha voluntad tan solo se da en determinadas ocasiones.

\subsection{Confiscación de propaganda}

Pese a la mencionada reserva al artículo 20 del PIDCP, en septiembre de 1997 el servicio de aduanas suizo confiscó $88 \mathrm{~kg}$ de propaganda del Partido de los Trabajadores del Kurdistán PKK. Dicho material consistente en

mendations in respect of Switzerland subject to interim follow-up», CRI 30 [consultado el 3 de octubre de 2013]. Disponible en: <https://wcd.coe.int/ViewDoc.jsp?id=1932569\&Site=CM>

59 Vid. Swiss Confederation. Federal Commission Against Racism. (2012). «Report of the Federal Commission against Racism FCR on the second Universal Periodic Review of Switzerland», Bern [consultado el 3 de octubre de 2013]. Disponible en: <http://www.ekr.admin.ch/ aktuell/index.html?lang=en>

${ }^{60}$ Vid. Riserve e dichiarazioni [consultado el 3 de octubre de 2013]. Disponible en: <http:// www.admin.ch/opc/it/classified-compilation/19650268/index.html>

${ }^{61}$ Vid. [consultado el 3 de octubre de 2013]. Disponible en: <http://treaties.un.org/Pages/ ViewDetails.aspx? src $=$ TREATY\&mtdsg_no $=I V-4 \&$ chapter $=4 \&$ lang $=$ en $>$

62 Vid. Sentencia del Tribunal Europeo de Derechos Humanos de 29 de abril de 1988, Belilos vs. Switzerland, no. 10328/83, Eps, 28- 33.

63 Vid. [consultado el 8 de octubre de 2013]. Disponible en: <http://www.parlament.ch/i/ suche/pagine/geschaefte.aspx?gesch_id=19990032> 
ejemplares de la revista «Toplumsal Alternatif» y en libros «Kadin Ve Iktidar Olgusu», pudo comprometer la seguridad interna y externa del país según los análisis de la fiscalía, dado que de su lectura, se desprendía que el uso de la violencia era la única alternativa al «türkischen Terrorstaat» (Estado terrorista turco).

Con tales premisas, los agentes aduaneros retiraron el material de propaganda en base a la norma «Propagandabeschluss; SR 127, AS 1948 1282»y, a los artículos 275bis y 296 del Código Penal.

La incautación del material acabó siendo oído por el TF, al alegar la parte demandante, que la Confederación helvética había mermado gravemente el derecho a la libertad de expresión y de prensa ${ }^{64}$.

A través de Sentencia BGE 125 II 417, el TF, casualmente acabó argumentando que dicha medida de confiscación de propaganda, no vulneró la libertad de expresión sirviéndose en su fallo de la jurisprudencia del TEDH, en relación a los artículos 6 y 13 e incluso 10 del $\mathrm{CEDH}^{65}$. El razonamiento del TF se basó en la necesidad de la Confederación de cumplir con sus obligaciones con el Derecho internacional, en contra de la aplicación de la Ley nacional ${ }^{66}$. Valiéndose para ello de las consideraciones previas del BR, por las que había precisado que el caso en cuestión correspondía con fuentes apropiadas para radicalizar al extremismo dentro de grupos extranjeros afincados en Suiza, que constituían una amenaza para la convivencia pacífica, seguridad interna ${ }^{67}$, y neutralidad Suiza ${ }^{68}$. Fallando

${ }^{64}$ El propio Tribunal reconoce de facto que, en efecto, supone una grave violación de la libertad de expresión (artículo $10 \mathrm{CEDH}$ ) y la libertad de prensa (artículo 55 de la anterior constitución). Vid. Sentencia del Tribunal Federal BGE 125 II 417, p. 428 [consultado el 8 de octubre de 2013]. Disponible en: <http://www.bger.ch/it/index/juridiction/jurisdiction-inherittemplate/jurisdiction-recht/jurisdiction-recht-leitentscheide1954.htm>

${ }^{65}$ El demandante alegaba injerencias graves en la libertad de expresión y de prensa por la confiscación del material: Erwägung 6: «Der Beschwerdeführer macht geltend, die Einziehung des von den Zollbehörden sichergestellten. Propagandamaterials stelle einen sehr schweren Eingriff in die Meinungsäusserungs- und Pressefreiheit dar, der einer Grundlage in einem formellen Gesetz bedürfe». Vid. Ibídem, FJ.6, p. 427.

${ }^{66}$ Erwägung 4: «In seiner jüngsten Rechtsprechung hat das Bundesgericht verschiedentlich erklärt, dass sich die Eidgenossenschaft nicht unter Berufung auf inländisches Recht ihrer völkerrechtlichen Verpflichtungen entziehen könne.» Vid. Ibídem, FJ.4, p. 424.

${ }^{67}$ Erwägung 7: «Der Bundesrat hält diese Schriften für geeignet, zum Extremismus neigende Gruppierungen in der ausländischen und schweizerischen Bevölkerung zu radikalisieren. Daraus ergebe sich eine Gefährdung für das friedliche Zusammenleben und damit für die innere Sicherheit der Schweiz». Vid. Ibídem, FJ.7 p. 429.

${ }^{68}$ Erwägung 7: «Da sie sich zudem keineswegs auf eine Kritik an den türkischen Behörden beschränken - was zulässig wäre - sondern diese beschimpfen, sind sie auch geeignet, die aussenpolitischen Beziehungen und die Neutralität der Schweiz zu beeinträchtigen.» Vid. Ibídem, p. 430. 
finalmente el TF en la necesidad de retirar cualquier propaganda subversiva para proteger la seguridad interna del país ${ }^{69}$.

A través de aquella sentencia, el TF enfatizó que en caso de conflicto entre el derecho nacional e internacional, se interpretaría el derecho federal de conformidad con el internacional y que en los supuestos en los que no fuera posible - a través de la interpretación constitucional - el derecho internacional debería prevalecer en caso de conflicto entre el derecho internacional de los derechos humanos y cualquier ley federal posterior ${ }^{70}$.

Consecuencia de este caso o no, lo cierto es que en marzo de 2006 se introdujo un nuevo apartado en la Ley federal de medidas de protección de la seguridad interior - LMSI - de 1997. A través del que se confiere capacidad a las autoridades policiales para confiscar materiales de propaganda con contenidos que inciten a la violencia, y relacionados con: actividades terroristas, de espio-

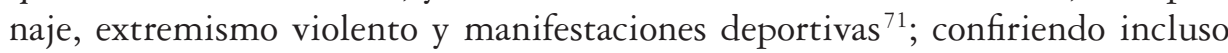
capacidad de bloqueo y cancelación de espacios en internet ${ }^{72}$.

Curiosamente la propia ley cuidó de que esos especiales poderes policiales no se reviertan contra la actividad política, ni contra el ejercicio de la libertad de expresión, asociación y reunión ${ }^{73}$. Normas que el Servicio de lucha contra el racismo lleva reclamando desde el año 2002 para que las autoridades puedan confiscar materiales de propaganda racista o que inciten a la violencia, independientemente de su naturaleza y composición ${ }^{74}$.

A modo de ejemplo, de la lectura del informe 2012 sobre seguridad en Suiza — promovido por el Consejero Federal Maurer (UDC/SVP)—, se asocian los actos de propaganda de la religión Islámica con el terrorismo, sosteniendo

${ }^{69}$ Erwägung 6: «Der Beschwerdeführer verkennt, dass der Propagandabeschluss sich nicht nur gegen die kommunistische Unterwanderung wandte, sondern überhaupt gegen jegliche Gefährdungen der inneren und äusseren Sicherheit der Schweiz, also beispielsweise auch gegen solche durch rechtsextreme Schriften.» Ibídem, FJ.6, 427.

70 Vid. FLEINER, T., MISIC, A., TÖPPERWIEN, N., (2005), Swiss Constitutional Law, Berna, Kluwer Law International, p. 45.

${ }^{71} \mathrm{Vid}$. Legge federale sulle misure per la salvaguardia della sicurezza interna LMSI del 21 marzo 1997, Art. 2.4.e. [consultado el 10 de octubre de 2013]. Disponible en: <http://www. admin.ch/opc/it/classified-compilation/19970117/index.html>

72 Vid. Ibídem, Art. 13.e.

73 «Gli organi di sicurezza della Confederazione e dei Cantoni non possono trattare informazioni relative alle attività politiche e all'esercizio dei diritti inerenti alla libertà d'opinione, d'associazione e di riunione.» Vid. Ibídem, Art. 3.1.

${ }^{74}$ Vid. Servizio per la Lotta al Razzismo, SG DFI. (2002). «Secondo e terzo rapporto presentati dalla Svizzera al Comitato delle Nazioni Unite per l'eliminazione della discriminazione razziale», Berna, p. 135. [consultado el 8 de octubre de 2013]. Disponible en: <http://www.ekr. admin.ch/shop/00007/00037/index.html?lang=it > 
arbitrariamente que los sentimientos Islamófobos surgidos por la restricción de la construcción de minaretes o del uso del burka pudieran servir de pretexto para justificar actividades violentas por islamistas ${ }^{75}$. Curiosamente el mismo informe en 2013 - promovido por el mismo Consejero- declara el extremismo de izquierdas, el enemigo de la UDC/SVP y de las políticas de asilo ${ }^{76}$.

Promovidos o no, lo cierto es que el partido UDC/SVP presentó una iniciativa contra las leyes mordaza en $2008^{77}$.

\subsection{Prácticas discriminatorias a través de iniciativas y referéndum}

La especial particularidad constitucional suiza, sin lugar a dudas, se materializa a través de su sistema participativo encarnado dentro del Título $4 .^{\circ}$ Capítulo 2. ${ }^{\circ} \mathrm{CF}$. De forma que a través de iniciativas populares y referéndums, se garantiza un dinamismo constitucional que sin duda refleja el sentir popular. Sin embargo, ese romanticismo democrático encuentra su punto de inflexión cuando el sentir popular se aleja del espíritu natural de la propia Constitución y a fortiori del Derecho internacional de los derechos humanos. Para ello tal y como hemos indicado, a priori — y sin olvidar que no se trata de un órgano imparcial — la AF dispondría de capacidad suficiente para declarar la nulidad total o parcial de las iniciativas populares que no respeten las dis-

75 Recordemos que el partido del Sr. Maurer, fue uno de los promotores del Referendum anti minarets. "If the impression that Switzerland and its inhabitants were hostile to Islam were to take hold among jihadists, this could provide them with a motive to attack. It cannot therefore be ruled out that in the longer term radical Islamic circles could make use of the minaret building ban in combination with other issues (such as a ban on burqas), to justify their activities, including violent acts. Still, the available information shows no concrete evidence of an increased threat to Switzerland». Vid. Federal Intelligence Service. (2012). «Switzerland’s Security 2012», p. 42. [consultado el 8 de octubre de 2013]. Disponible en: <http://www.vbs.admin.ch/internet/vbs/en/ home/documentation/publication/snd_publ.parsys.28125.downloadList.79128. DownloadFile. tmp/ndbsicherheitschweiz2012e.pdf>

76 Left-wing extremists continue to make the most of any opportunity to demonstrate against their enemy, the Swiss People's Party, or against Swiss policy on asylum. Vid. Federal Intelligente Service.(2013). «Switzerland's Security 2013», p. 50 [consultado el 8 de octubre de 2013]. Disponible en: <http://www.vbs.admin.ch/internet/vbs/en/home/documentation/publication/ snd_publ.parsys.86537.downloadList.89279. DownloadFile.tmp/06ndblageberichtewebversion. pdf $>$

77 A través de iniciativa popular, el SVP pretendía restringir cualquier tipo de iniciativa legislativa destinada a conminar la libertad de expresión en política. La iniciativa —que no fue vetada por la BV — fue rechazada por insuficiencia del número de firmas. Vid. «Iniziativa popolare federale 'per la libertà d'espressione - niente museruola!'» [consultado el 8 de octubre de 2013]. Disponible en: <http://www.admin.ch/ch/i/pore/vi/vis360.html> 
posiciones imperativas del Derecho internacional, al menos en iniciativas llevadas a cabo antes de la derogación del artículo 139. ${ }^{a}$ CF en diciembre de 2008. La praxis en cambio nos muestra que no son pocas las ocasiones en las que los requerimientos de la ciudadanía han sobrepasado los límites establecidos, sin la oposición de la AF. Posiblemente ese freno a la fiscalización de las iniciativas populares y referéndums, esté influenciado por la propia cultura política suiza, recelosa tal y como apunta Ruiz, de las instancias judiciales, académicas e incluso de las parlamentarias y ejecutivas en beneficio del respeto a las decisiones populares ${ }^{78}$.

La conocida y reconocida hospitalidad del pueblo suizo ${ }^{79}$, reflejada en el espíritu de solidaridad y apertura al mundo que inspira el texto constitucional, se ve empañada — al igual que en el resto de Europa — por la supuesta amenazada del quebrantamiento social consecuencia de la inmigración ${ }^{80}$. Barreras lingüísticas, culturales, sociales, de origen, económicas, entre otras muchas; persiguen al inmigrante desde su llegada y más allá de la determinación de su naturalización —en caso de lograrla. Obstáculos que en muchos casos resultan infranqueables en la Unión Europea, por ser el proceso de naturalización largo y frustrante. Proceso que en el panorama legislativo helvético resulta más arduo aún ${ }^{81}$, en función del municipio de residencia del inmigrante ${ }^{82}$, dado que de forma tradicional, en

78 Vid. RUIZ VIEYTEZ, J. (2013), «Democracia Directa y Religión: Problemas Derivados de la Decisión Suiza de Prohibir los Minaretes», Revista de Derecho Político, núm. 87, p. 281.

79 «Accustomed for generations to dealing with different cultures, the Swiss are undoubtedly open to cultural diversity and have acquired experience with it over time. However, the present situation is radically different from that prevailing in the past». Vid. RELLSTAB, U. (2001), «Transversal Study Cultural Policy and Cultural Diversity. National report Switzerland», Council of Europe, Strasbourg, p. 14 [consultado el 8 de octubre de 2013]. Disponible en: <http:// www.coe.int/t/dg4/cultureheritage/culture/completed/diversity/CCCULT_2001_7_EN. PDF>

80 «In Switzerland, immigration is feared by many «indigenous» citizens who see it as likely to dilute their national values and see immigrants as unlikely to be loyal to their adopted country». Vid. Council of Europe. Report of the Group of Eminent Persons of the Council of Europe. «Living together Combining diversity and freedom in 21st- Century Europe», p. 48 [consultado el 8 de octubre de 2013]. Disponible en: <http://tsforum.event123.no/UD/rehc2013/pop.cfm?F useAction $=$ Doc\&pAction $=$ View\&pDocumentId $=46417>$

81 «Per quanto riguarda l'acquisizione della cittadinanza, nel confronto internazionale la Svizzera occupa le ultime posizioni tra i Paesi europei». Vid. Servizio per la Lotta al Razzismo (2002). «Secondo e terzo rapporto presentati dalla Svizzera al Comitato delle Nazioni Unite per l'eliminazione della discriminazione razziale», Berna, p. 77 [consultado el 8 de octubre de 2013]. Disponible en: <www.edi.admin.ch/shop/00019/00077/index.html?lang=it>

82 «In order to be granted such rights in Switzerland, it is first necessary to become member of a municipality and then clear various obstacles (eg financial, knowledge of the language, history, values and customs of the commune and the country). In addition, one must fill the conditions of naturalisation fixed by the cantons and the Confederation.» Vid. RELLSTAB, U. (2001), «Trans- 
diversas localidades suizas se ha venido consensuando la forma de naturalizar las peticiones de nacionalización, mediante la fórmula del referéndum, resultando en infinidad de supuestos contrario a lo establecido, entre otros, por el up supra mencionado artículo octavo CF.

La indolencia de la AF ante iniciativas que violan el Derecho internacional y la escalada del partido UDC/SVP, consintió que mediante campañas antidemocráticas ${ }^{83}$, se promoviera enfatizar en la restricción del acceso a la naturalización de los inmigrantes, logrando en numerables ocasiones la perpetración de sus fines, resultando in fine, insignificantes los casos repelidos por los Tribunales.

\subsection{Naturalización ante el pueblo}

Uno de los casos más sonados fue la iniciativa «Einbürgerungen vors Volk!», presentada por la UDC/SVP en la ciudad de Zúrich en octubre de 1999. La misma, solicitaba que el proceso de adquisición de nacionalidad por naturalización se llevara a cabo directamente por el pueblo, con la intención de que los ciudadanos con derecho a voto, pudiesen decidir mediante referéndum qué candidatos resultaban idóneos, conociendo a priori cada elector, las especiales características del candidato, —edad, nacionalidad, fecha de ingreso en el país, educación, ingresos, base imponible, ocupación, conocimientos lingüísti$\cos \ldots{ }^{84}$, datos necesarios — -según la SVP_, en base al interés público establecido por el artículo $36 \mathrm{CF}$ con el fin de elaborar un perfil de personalidad de cada candidato ${ }^{85}$.

versal Study Cultural Policy and Cultural Diversity. National report Switzerland», Council of Europe, Strasbourg, p. 17.

${ }^{83}$ A través de un estudio comparativo entre diferentes municipios suizos, se pretende demostrar las dificultades del acceso a la naturalización a los inmigrantes. Dificultades que en los casos de inmigrantes de la antigua Yugoslavia, turcos o africanos, resulta prácticamente imposible. Apuntan que la UDC/SVP, «has repeatedly emphasized the need to restrict Access to citizenship and immigration inflows, campaigning against 'mass naturalizations' with signs that portray brown, black, and white hands snatching Swiss Passports.» Vid. HAINMUELLER, J. y HANGARTNER, D. (2013), «Who Gets a Swiss Passport? A Natural Experiment in Immigrant Discrimination», American Political Science Review, Vol, 107, No. 1, p. 162.

${ }^{84}$ Erwägung 4: «4.3.2 Im Einbürgerungsverfahren müssen der zuständigen Behörde detaillierte Angaben über Herkunft, Einkommen, Vermögen, Ausbildung, Tätigkeit, Sprachkenntnisse, Familienverhältnisse, Freizeitgestaltung, Leumund, usw. gemacht werden.» Vid. Sentencia del Tribunal Federal BGE 129 I 232, FJ, 4 [consultado el 12 de octubre de 2013]. Disponible en: $<$ http://www.bger.ch/it/index/juridiction/jurisdiction-inherit-template/jurisdiction-recht/jurisdiction-recht-leitentscheide1954.htm>

${ }^{85}$ Ibídem, FJ, 4, 4.3.2. 
Rechazada por la administración y en parte por los Tribunales, el caso acabó siendo oído en amparo por el TF, en recurso promovido por dos dirigentes del partido SVP.

Envuelto más en cuestiones procesales que jurídicas, el TF no se pronunció en relación al contenido de la propaganda, apuntando que dicha iniciativa no hubiera sido problemática, si tratara temas financieros de potestad cantonal o municipal. Revertiendo finalmente la situación en base al respeto de los derechos individuales y las garantías procesales —artículo $29.2 \mathrm{CF}$ - y, considerando finalmente inconstitucional la legislación cantonal que sometía a referéndum en las urnas decisiones sobre los individuales ${ }^{86}$.

\subsection{Naturalización en el municipio de Emmen}

Por medio de Sentencia BGE 129 I 217, el Tribunal Federal Suizo analizó la demanda presentada en relación a un proceso de votación celebrado el 12 de marzo de 2000, sobre 23 solicitudes para la naturalización de 56 personas en el municipio de Emmen. De las 56, tan solo ocho fueron aceptadas en votación pública; las únicas de ciudadanos italianos, siendo el resto de peticiones rechazadas en su mayoría inmigrantes de la antigua Yugoslavia.

Es destacable la iniciativa, «Einbürgerungen von Ausländern vors Volk!» —naturalización de los extranjeros ante el pueblo- presentada por el partido Schweizer Demokraten (SD) el 1 de junio de 1999 y aceptada por el 58\% de los votantes de Emmen. La misma llamaba a evitar la integración de los ciudadanos provenientes de los Balcanes, dado que, al no ser cristianos no podían aceptar las leyes y costumbres locales ${ }^{87}$. Así mismo, para el proceso de votación del 12 de marzo de 2000, el «Komitee zum Erhalt der Schweizer Rasse» (Comité para la preservación de la raza suiza) divulgó un folleto a través del que se llamaba a los votantes a mostrar valor el 12 de marzo: «no más Yugos en nuestra comunidad» ${ }^{88}$.

86 Erwägung 5:«Weil dies bei der Volksabstimmung an der Urne nicht möglich ist, erweist sich die kantonale Regelung, mit der solche Einzelentscheide dem Referendum unterstellt werden, als verfassungswidrig.» Vid. Ibídem, FJ, 5.

87 Vid. Sentencia del Tribunal Federal BGE 129 I 217, Ep.2.3.2.

88 Zur Abstimmung vom 12. März 2000 liegt ein Flugblatt eines «Komitee zum Erhalt der Schweizer Rasse» vor, in dem es heisst: «Zeigen Sie am 12. März Mut: Nein zu weiteren Jugos in unserer Gemeinde». Nach dem Flugblatt seien Personen aus dem ehemaligen Jugoslawien um ein Vielfaches krimineller und gewalttätiger als Schweizer, beanspruchten überproportional oft die Invaliden- und die Krankenversicherung und seien auch in der zweiten Generation noch nicht integriert. Vid. Ibídem. 
Desoída en primera instancia, acudieron las partes demandantes al TF en defensa del derecho a ser tratado equitativamente en el proceso de votación y no ser discriminados por su condición étnica. Pese a lo evidente de la propaganda el TF no consideró vulnerado el artículo 8.2 CF, al considerar que la decisión de no aceptación fue tomada por los ciudadanos — en fase de votación-y no por la administración demandada ${ }^{89}$; comisionando anómalamente a la parte demandante a probar que ciertamente se produjo una situación discriminatoria, en base a lo establecido en el artículo 6 de la Ley federal sobre la paridad entre hombre y mujer; Ley 151.1 de 24 de marzo de $1995^{90}$.

En contraposición con la práctica legislativa de la Unión Europea - donde la carga de prueba es invertida_ — ${ }^{91}$, la existencia o no de discriminación resultó únicamente presumible, entendiéndose por tanto que era la parte demandante la que debiera demostrar que padeció una real o presumible situación discriminatoria. En este caso, la carga de prueba no solo fue en contra de la parte demandante, es más, el TF rehusó — en contradicción con el caso PKK- estimar como discriminatorios y estigmatizadores los folletos y cartas que referían actitudes negativas hacia los ciudadanos de la antigua Yugoslavia ${ }^{92}$.

89 Erwägung 2: «Es liegt daher auch kein Grund vor, höhere Anforderungen an den Nachweis einer Diskriminierung zu stellen, nur weil der Entscheid von den Stimmbürgern und nicht von einer Verwaltungsbehörde gefällt wurde.» Vid. Sentencia del Tribunal Federal BGE 129 I 217, Ep. 2 [consultado el 12 de octubre de 2013]. Disponible en: <http://www.bger.ch/it/index/juridiction/ jurisdiction-inherit-template/jurisdiction-recht/jurisdiction-recht-leitentscheide1954.htm >

90 «Si presume l'esistenza di una discriminazione per quanto la persona interessata la renda verosimile; questa norma si applica all'attribuzione dei compiti, all'assetto delle condizioni di lavoro, alla retribuzione, alla formazione e al perfezionamento professionali, alla promozione e al licenziamento.» Vid. Legge federale sulla parità dei sessi del 24 marzo 1995, 151.1 [consultado el 12 de octubre de 2013]. Disponible en: <http://www.admin.ch/opc/it/classifiedcompilation/19950082/index.html>

91 «Los Estados miembros adoptarán con arreglo a sus sistemas judiciales nacionales las medidas necesarias para que, cuando una persona que se considere perjudicada por la no aplicación, en lo que a ella se refiere, del principio de igualdad de trato presente, ante un órgano jurisdiccional u otro órgano competente, hechos que permitan presumir la existencia de discriminación directa o indirecta, corresponda a la parte demandada demostrar que no ha habido vulneración del principio de igualdad de trato.» Vid. entre otros. Unión Europea. Directiva 97/80/CE del Consejo de 15 de diciembre de 1997, relativa a la carga de la prueba en los casos de discriminación por razón de sexo. Diario Oficial de la Comunidad Europea L 14/8 de 20 de enero de 1998, artículo 4. Así mismo: Vid. Unión Europea. Directiva 2000/43/CE del Consejo de 29 de junio de 2000, relativa a la aplicación del principio de igualdad de trato de las personas independientemente de su origen racial o étnico. Diario Oficial de la Comunidad Europea L 180/25 de 19 de julio de 2000, artículo 8.

92 Erwägung 2: «Flugblättern und Leserbriefen mit negativer Haltung gegenüber Bürgern aus dem ehemaligen Jugoslawien mass der Regierungsrat keine Bedeutung zu». Vid. Sentencia del Tribunal Federal BGE 129 I 217, FJ. 2. 
Presionado posiblemente por el gran debate social e internacional genera$\mathrm{do}^{93}$, el Tribunal acabó fallando de forma favorable para la parte demandante, en base a una violación al derecho a ser oído en el proceso ${ }^{94}$. En ambos casos -Zúrich y Emmen - el TF observó el riesgo que suponía que cualquier solicitud fuera rechazada por la afiliación con ciertos grupos étnico-culturales ${ }^{95}$, sin embargo rehusó dirimir si el proceso fue o no discriminatorio.

\subsection{Naturalización y velo islámico}

El conocido conflicto cultural y jurídico-constitucional del uso del velo islámico en Suiza, ha sido ya objeto de audiencia del TEDH. El caso Dablab vs. Suiza, otorgó concordar con el CEDH la restricción en el uso del velo a una docente dentro del aulario helvético. El TEDH consideró que mediante su uso se podrían ejercer practicas proselitistas en el contexto escolar, al estimar, que los alumnos podrían resultar fácilmente influenciados ${ }^{96}$, priorizando la sensibilidad religiosa de los alumnos respecto de la libertad religiosa del docente ${ }^{97}$.

Respetando la posición del Tribunal europeo, por la inconsistencia de la sentencia, no podemos compartirla, dado que apreciar un posible proselitismo en el uso del velo va mucho más allá de la tolerancia y la interculturalidad, máxime cuando las aulas europeas continúan plagadas de crucifijos y como apunta Rey, sostener que el hijab es una «prenda corruptora de menores es un mensaje excesivo y todo lo excesivo es insuficiente» ${ }^{98}$.

${ }^{93}$ El caso del proceso de Emmen — que no deja de ser uno más - llegó a ser motivo de inclusión en el informe periódico presentado por Suiza al Comité de Naciones Unidas para la Eliminación de la Discriminación Racial. Vid. Servizio per la Lotta al Razzismo. (2002). «Secondo e terzo rapporto presentati dalla Svizzera al Comitato delle Nazioni Unite per l'eliminazione della discriminazione razziale», Berna, p. 77.

94 Erwägung 3: «Nach dem Gesagten hat der Regierungsrat im angefochtenen Entscheid zu Unrecht eine Verletzung der Begründungspflicht verneint und damit auch Art. 29 Abs. 2 BV verletzt.» Vid. Sentencia del Tribunal Federal BGE 129 I 217, FJ. 3.

95 Vid. HAINMUELler, J. y HANGARTNER, D. (2013), «Who Gets a Swiss Passport? A Natural Experiment in Immigrant Discrimination», American Political Science Review, Vol. 107, N. ${ }^{\circ}$, p. 164.

96 «En effet, la requérante a enseigné dans une classe d'enfants entre quatre et huit ans et donc d'élèves se trouvant dans un âge où ils se posent beaucoup de questions tout en étant plus facilement influençables que d'autres élèves se trouvant dans un âge plus avancé.» Vid. Decisión del Tribunal Europeo de Derechos Humanos de 15 de Febrero de 2001, Dahlab vs. Suisse, N. ${ }^{\circ} 42393 / 98$, p. 14.

97 Vid. ESPOSITO, A. (2008), Il Diritto Penale «Flessibile», Torino, G. Giappichelli, p. 436.

98 REY MARTÍNEZ, F. (2010), «El Problema Constitucional del Hijab», Revista General de Derecho Constitucional, 10, p. 5. 
Sin embargo, pese a lo concreto del caso Dablab y la infundada laicidad de la Confederación helvética, tras más de 25 años de residencia en el municipio de Birr, un matrimonio musulmán solicitó su naturalización. Tras ser evaluadas sus solicitudes positivamente, el ayuntamiento apuntó que su integración era indiscutible ${ }^{99}$. Sin embargo una vez más, previo al proceso de votación ante la asamblea del pueblo, se envió a los electores un folleto informativo sobre el perfil de los solicitantes, en los que se apreciaba la imagen de la mujer demandante portando el velo islámico ${ }^{100}$.

A través de votación pública, se rechazó la naturalización por 95 votos contra 41, siendo comunicado el resultado de la votación a los solicitantes a través de un acto de motivación. En el mismo, el Ayuntamiento afirmaba que mediante el uso del velo, la mujer tenía un papel socialmente diferente, no acorde ni con la declaración universal de los derechos humanos ni con la Constitución, al no existir una igualdad entre ambos sexos, por lo que, al no quedar garantizada la integración no procedía su naturalización ${ }^{101}$.

En el proceso BGE 134 I 56 de 27 de febrero de 2008, el TF escuchó en amparo la demanda presentada por ambos cónyuges en base a violaciones de los artículos 8.2 y 15 de la CF. Por cuestiones procesales, se valoró en separata el proceso de naturalización de ambos cónyuges, rechazando el de la mujer en base a la ausencia de conocimientos lingüísticos — pese a ser la parte causante que usó el velo- y revocó la votación del varón al apreciar inadmisible el trato discriminatorio recibido por el uso del velo de su mujer, según el artículo 8.2.

Vagamente el TF consideró que el simple uso del velo -en contra del mencionado folleto descriptivo — no era señal de sumisión, sino señal del derecho a manifestar libremente su religión sin sometimiento alguno, por lo que,

99 «der Gemeinderat hielt in seinen Erläuterungen zuhanden der Einwohner-Gemeindeversammlung fest, dass die Integration der Gesuchsteller unbestritten sei.» Vid. Sentencia del Tribunal Federal BGE 134 I 56, S. 57 [consultado el 12 de octubre de 2013]. Disponible en: <http:// www.bger.ch/it/index/juridiction/jurisdiction-inherit-template/jurisdiction-recht/ jurisdiction-recht-leitentscheide1954.htm>

${ }^{100}$ In der Versammlungsunterlage werden jeweils die Gesuchsteller persönlich, mit Foto, vorgestellt. Frau K. liess sich dabei mit einer religiösen Kopfbedeckung ablichten». Ibídem, p. 57.

101 «In der Versammlungsunterlage werden jeweils die Gesuchsteller persönlich, mit Foto, vorgestellt. Frau K. liess sich dabei mit einer religiösen Kopfbedeckung ablichten. Das Kopftuch weist Frauen eine geschlechtlich und sozial differente Rolle zu, die im Gegensatz zum Gleichheitsgrundsatz der universell gültigen Allgemeinen Menschenrechte und insbesondere der Schweizerischen Bundesverfassung steht. Somit wird bestritten, dass Herr und Frau K. die Gleichstellung von Mann und Frau respektieren, achten und danach auch leben. Die Integration wird deshalb bestritten». Vid. Ibídem, p. 57. 
consideró que al no existir indicios de que el uso del velo entrara en conflicto con los valores constitucionales, no podía considerarse motivo de rechazo de la naturalización del hombre ${ }^{102}$. Pese a sentenciar que el proceso de naturalización atentaba contra el artículo 8.2 CF, nuevamente el TF, rehusó apreciar un tipo de discriminación directa — mediante el envío de propaganda — hacia la portadora de velo.

Lo cierto es que, pese a estar reconocida la plena libertad religiosa tal y como hemos indicado, la cuestión islámica viene siendo un tema habitual de la realidad política suiza de los últimos años. Así desde el perturbador referéndum antiminaretes del pasado 29 de noviembre de 2009 de «No all'islamizzazione della Svizzera», el comité que presentó la iniciativa —entre los que figuraba la UDC/ SVP — argumentaba que las mezquitas eran los cuarteles, y los minaretes el baluarte de la política de islamización ${ }^{103}$.

Las recomendaciones de Parlamento y BR fueron rechazar tal iniciativa, al considerar que vulneraba numerosos derechos fundamentales ${ }^{104}$. Sin embargo, la AF — una vez más — no hizo uso de su capacidad de declararla nula, a través del —entonces en vigor - artículo 139. ${ }^{a} \mathrm{CF}^{105}$. La negligencia con la que la AF toleró tal iniciativa, colisionó con declaraciones de Consejeros Federales como Widmer-Schlumpf, que apuntaba que los musulmanes en Suiza aceptaban sin

102 Der Umstand, dass die Ehefrau des Beschwerdeführers ein Kopftuch trägt, könnte mitberücksichtigt werden, wenn darin vor dem Hintergrund der konkreten Verhältnisse eine Haltung des Beschwerdeführers zum Ausdruck kommt, die mit unsern grundlegenden rechtsstaatlichen und demokratischen Wertvorstellungen im Widerspruch stünde. Ein derartiger konkreter Bezug wird im kommunalen Verfahren weder behauptet noch nachgewiesen. Ibídem, FJ. 5, p. 63.

${ }^{103}$ Refiriéndose a palabras de Erdogan (actual primer ministro turco) los promotores de la iniciativa, apuntaban que: «La nostra democrazia è solamente il treno su cui viaggiamo fino a che non avremo raggiunto il nostro obiettivo. Le moschee sono le nostre caserme, i minareti sono le nostre baionette, le cupole i nostri caschi e i credenti i nostri soldati». Questa affermazione non ha nulla a che vedere con la religione, bensì piuttosto con la rivendicazione del potere politico. I minareti diventano dunque il baluardo dell'islamizzazione politica.» Vid. Votazione populare del 29 de novembre de 2009. Spiegazione del Consiglio federale. [consultado el 12 de octubre de 2013]. Disponible en: <http://www.ejpd.admin.ch/content/ejpd/it/home/dokumentation/ abstimmungen/2009-11-29.html>

104 «L'iniziativa contraddice numerosi diritti fondamentali sanciti dalla Costituzione federale e viola i diritti dell'uomo. Essa non contribuisce in alcun modo a proteggere l'ordinamento dello Stato svizzero, ma al contrario minaccia la pace religiosa nel nostro Paese. Consiglio federale e Parlamento respingono pertanto l'iniziativa.

105 Recordemos que el examen preliminar de la iniciativa se realizó el 1 de noviembre de 2008 [consultado el 12 de octubre de 2013]. Disponible en: http://www.admin.ch/opc/it/ federal-gazette/2007/2967.pdf 
reservas el Derecho federal, siendo contrario al Derecho internacional restringir el derecho a la libertad de culto reconocido por la propia Ley federal ${ }^{106}$.

Pese a las numerosas recomendaciones y ser consciente la AF de la existencia real de infracción al $\mathrm{CEDH}^{107}$, el referéndum se llevó a cabo finalmente, con su conocido resultado.

\section{CONCLUSIONES}

Las numerosas virtudes del sistema de democracia directa suizo, encuentran su punto de inflexión allá donde el propio pueblo se extralimita de manera autónoma, vulnerando los límites del derecho nacional e internacional. La capacidad del discurso extremo en el escenario político y del uso mediático de la propaganda, propician el caldo de cultivo perfecto para generar un rechazo directo hacia grupos minoritarios, materializándose a través de referéndums e iniciativas polucionadas a priori ${ }^{108}$.

Conscientes de que la libertad de expresión es uno de los pilares en los que se asientan las sociedades democráticas, la misma, tal y como hemos indicado no es un derecho infinito.

Ahora bien limitar la naturaleza de la libre expresión humana, puede acarrear consecuencias mayores si no se realiza en orden de proteger la sociedad o la integridad de terceros. Con ello no pretendemos decir que la libertad de expresión se deba extralimitar, ni queremos entrar en juicios de valor sobre «el carácter totalizador del liberalismo constitucional de los Estados Unidos...» — en lo que a la libertad de expresión respecta — ni por supuesto, del «imperialismo democrático-constitucional alemán» ${ }^{109}$. Pero sí ratificarnos en los límites internacionalmente aceptados en aras de la protección de las minorías introducidos a través

106 [consultado el 12 de octubre de 2013]. Disponible en: <http://www.ejpd.admin.ch/ content/ejpd/it/home/dokumentation/abstimmungen/2009-11-29/tvstatement.html>

107 Vid. PETERS, A. (2010), «El Referéndum Suizo sobre la Prohibición de Minaretes». Traducción de: REVIRIEGO PICÓN, F., Teoría y Realidad Constitucional, núm. 25, Madrid, pp. 429-438.

108 «Referendums generally harm minorities would be a unwise. However, our microlevel results shed light on at least one central issue: access to citizenship in a country where local voters used their direct democratic means to discriminate against particular minority groups.» HAINMUELLER, J. y HANGARTNER, D. (2013), «Who Gets a Swiss Passport? A Natural Experiment in Immigrant Discrimination», American Political Science Review, Vol, 107, N. ${ }^{\circ}$ 1, p. 186.

109 Sánchez González, considera que aquel temor estadounidense al comunismo y a cualquier idea que pudiera diluir su sistema político, era familiar del germánico con su modelo de democracia militante. Vid. SÁNCHEZ GONZÁLEZ, S. (1992), La Libertad de Expresión, Madrid, Marcial Pons, p. 100. 
de la aceptación y ratificación del Derecho internacional y su inserción en el Derecho nacional. Cualquier intento de silenciamiento fuera de los márgenes apreciados: apología del odio que constituya incitación a la discriminación, la hostilidad, la violencia e incluso la guerra; colisionaría directamente con el artículo 10 del CEDH.

Entendemos así que ningún Estado puede hacer uso de su capacidad restrictiva con fines sistemático-protectores en contra del disidente, ni puede delimitar opiniones o manifestaciones de cualquier clase que no inciten a la discriminación ni a la violencia. En caso contrario, supondría un ultraje hacía los valores democráticos, en los que cualquier injerencia del Estado que trate de adoptar un tipo de decisión infundada o arbitraria, daría lugar a un efecto general de silenciamiento «chilling effect», en contra de la ciudadanía. Es por ello por lo que la mera exhibición de una bandera (por poner un ejemplo), difícilmente podría «incitar a la violencia, el racismo, la xenofobia o cualquier otra forma de discriminación que atente contra la dignidad humana» ${ }^{110}$.

De esta forma lo interpretan autores como Müller y Schefer, en relación a la toma de grabaciones por parte de la Policía en manifestaciones; sin duda, el efecto disuasorio sobre los manifestantes al sentirse grabados por la Policía podría ser comparable con la propia intervención directa. Y más importante, cuando la redacción de una norma resulta tan vaga e imprecisa que deja un amplio margen interpretativo para las autoridades en la aplicación de la ley, y a los individuales, para auto-limitarse por miedo a las posibles consecuencias de la ley ${ }^{111}$.

Pero los límites que el derecho perentorio nos requiere, son concisos en lo que a la libertad de expresión se refiere. Su aplicación, únicamente requiere disponer de la capacidad y el conocimiento adecuado para determinar cuándo un

110 Recientemente el Tribunal Superior de Justicia de Madrid, se ha pronunciado en contra de la restricción del uso de la bandera de la Segunda República Española, al considerar que la misma, no incita a la violencia resultando su restricción contraria a los principios constitucionales. Vid. Sentencia del Tribunal Superior de Justicia de Madrid, Sala de lo Contencioso Administrativo, Sección Novena, Recurso N. ${ }^{\circ} 1335$, FJ.5.

111 «Ein "chilling effect" kann auch aus einer vagen gesetzlichen Regelung resultieren, die den rechtsanwendenden Behörden einen derat grossen Spielraum lässt, dass für die Einzelnen die rechtlichen Konsequenzen einer Meinungsäusserung kaum abschätzbar sind. An die Bestimmtheit der gesetzlichen Grundlage von Grundrechtseingriffen sind daher aus dem Gedanken des grundrechtlichen Schutzes freier Kommunikation und der Gefahr unerwünschter «chilling effects» besonders strenge Anforderungen zu stellen.» Vid. MÜLLER, J. P. y SCHEFER, M. (2008), Grundrechte in der Schweiz. Im Rahmen der Bundesverfassung, der EMRK und der UNOPakte, Bern, Stämpfli Verlag AG, pp. 375 y ss. 
mensaje incita a la discriminación o la violencia; y para ello, es inevitable disponer de unas estructuras cualificadas.

Mensajes como los del semanal «Die Weltwoche» ${ }^{112}$, iniciativas populares como las presentadas por la UDC/SVP y el SD para la expulsión de extranjeros que cometan crímenes ${ }^{113}$, o la iniciativa ticinense del pasado 22 de septiembre de 2013 por la prohibición del uso del burca ${ }^{114}$; van más allá de lo permisible.

En relación a esto último, posiblemente esos sentimientos anti islámicos provienen del miedo a la pérdida de identidad, consecuencia de los procesos globalizadores y la expansión global de las diferentes religiones ${ }^{115}$. Según Stone, la Racial Hatred Act se promulgó en el Reino Unido ante la preocupación de que la población musulmana pudiera ser objeto de ataques motivados por el odio religioso consecuencia de la vinculación del terrorismo con el Islam, y para proteger de que los clérigos musulmanes no incitaran al odio contra los no musulmanes ${ }^{116}$.

Miedo o no, lo cierto es que la mínima normativa existente no parece abocada a proteger a las minorías frente al envite del discurso del odio. Y cuando la inacción de las autoridades permite que el poder mediático convoque a la sociedad en contra de la propia sociedad, el contrato social se quiebra. Cada vez que escuchamos que en Europa se restringe y se persigue al musulmán por ser diferente, nos surge la misma pregunta: ¿Qué ocurriría si parte de la sociedad europea estigmatizara el derecho a la libertad de expresión y religiosa, vetando

112 El 4 de abril de 2012, el mencionado semanal, divulgaba la imagen de un niño portando una pistola. La imagen anunciando: «Die Roma kommen: Raubzüge in die Schweiz» (los gitanos vienen: Incursiones en Suiza). [consultado el 12 de octubre de 2013]. Disponible en: <http://www. humanrights.ch/de/Schweiz/Inneres/Rassismus/Vorfaelle/idart_9364-content.html>

113 [consultado el 12 de octubre de 2013.] Disponible en: <http://www.iniziativa-espulsioni. $\mathrm{ch} /$ it/iniziativa-popolare/index.html>

${ }^{114}$ Mientras una vertiente afirma que las mujeres que adoptan el Islam «as subjecting female bodies to patriarchal gender structures have been considered as a paradox, or representing a 'perplexing question' by feminist scholars» y otros sostienen que «argue in a universalistic feminist matter, that though Muslim girl seem to choose wearing the veil, this does not mean that they are auto, as the veil is a (the) symbol of subordination». Vid. BENDIXSEN, S. (2010), «Islam as a New Urban Identity? Young Female Muslims Creating a Religious Young Culture in Berlin». AA. VV, Gender, Religion, and Migration, Plymouth, Lexington Books, p. 105.

115 «As religious formations have become multinational organizations through globalization and the geographical expansion or creation of satellite communities, they have developed multiple bureaucracies with their own administrative specifies, political environments, and cultural organizational practices». Vid. LAGUERRE, M. (2011), Network Governance of Global Religions. Jerusalem, Rome and Mecca, New York, Routledge, p. 114.

116 Vid. STONE, R. (2012), Textbook on Civil Liberties and Human Rights, Oxford University Press, pp. 434 y ss. 
el uso del velo católico, o peor aún; impidiera la construcción de sinagogas e iglesias? Tal vez, como apunta Gutiérrez, la palabra final parece corresponder siempre al TEDH ${ }^{117}$; sin embargo, no todos los casos llegan a ser oídos y no todos analizados con el mismo prisma. Quizá porque la protección del discurso político y periodístico resulta demasiado amplia ${ }^{118}$.

\section{BIBLIOGRAFÍA}

AEMISEGGER, H. (2005), «The federal judge vis- a vis the jurisdiction of the ECHR», en AA. VV., The Future Of The European Judicial System in a Comparative Perspective, Berlin, Nomos.

BENDIXSEN, S. (2010), «Islam as a New Urban Identity? Young Female Muslims Creating a Religious Young Culture in Berlin». AA. VV., Gender, Religion, and Migration, Plymouth, Lexington Books.

BERTONI, E. y RIVERA, J. (2012), «The American Convention on Human Rights. Regulation of Hate Speech and Similar Expression», en, HERZ, M. y MOLNAR, P., The Content and Context of Hate Speech. Rethinking Regulation and Responses, New York, Cambridge University Press.

EMMERSON, B., ASWORTH, A., MacDONALD, A. (2012), Human Rights and Criminal Justice, London, Sweet \& Maxwell.

ESPOSITO, A. (2008), Il Diritto Penale «Flessibile», Torino, G. Giappichelli.

FISS, O. (2011), «Libertad de expresión y estructura social» en AA. VV., Libertad de expresión: debates, alcances y nueva agenda, Quito, Oficina del Alto Comisionado de las Naciones Unidas para los Derechos Humanos.

FLEINER, T., MISIC, A., TÖPPERWIEN, N. (2005), Swiss Constitutional Law, Berna, Kluwer Law International.

GUIORA, A. N. (2009), Freedom from religion. Rights and national security, New York, Oxford University Press.

GUTIÉRREZ, I. y PRESNO, M. A. (2010), La inclusión de los otros: símbolos y espacios de la multiculturalidad, Granada, Comares.

117 Vid. GUTIÉRREZ, I. y PRESNO, M A. (2010), La inclusión de los otros: símbolos y espacios de la multiculturalidad, Granada, Comares, Introducción.

${ }^{118}$ En relación al caso Muller vs Switzerland, el TEDH sostuvo que la condena por exhibir obras de arte sobre actividades sexuales incluidas homosexuales, estuvo justificada por la protección de la moral pública y los derechos de otros. Es por ello por lo que se afirma que «artistic expresion has generally been afforded less stringent protection tan political and journalistic speeh.» Vid. EMMERSON, B., ASWORTH. A., MacDONALD. A. (2012), Human Rights and Criminal Justice, London, Sweet \& Maxwell, p. 759. 
HAINMUELLER, J. y HANGARTNER, D. (2013), «Who Gets a Swiss Passport? A Natural Experiment in Immigrant Discrimination», American Political Science Review, Vol, 107, No. 1.

KOLLER, H. y BIAGINNI, G. (2003), «La nueva constitución federal Suiza. Una visión general de las novedades y aspectos más destacados», UNED. Teoría y Realidad Constitucional, n. ${ }^{\circ} 10-11$.

LAGUERRE, M. (2011), Network Governance of Global Religions. Jerusalem, Rome and Mecca, New York, Routledge.

MARTÍN HERRERA, D. (2012), «Constitucionalidad del Discurso de Odio. Cuando el 'Hate Speech' se convierte en 'Hate Crime'» (2013). Asociación de Constitucionalistas de España, XI Congreso.

MÜLLER, J. P. y SCHEFER, M. (2008), Grundrechte in der Schweiz. Im Rabmen der Bundesverfassung, der EMRK und der UNO-Pakte, Bern, Stämpfli Verlag AG.

PAÚL DÍAZ, A. (2011), «La penalización de la incitación al odio a la luz de la jurisprudencia comparada», Revista Chilena de Derecho, N. 2.

PETERS, A. (2010), «El Referéndum Suizo sobre la Prohibición de Minaretes». Traducción de: REVIRIEGO PICÓN, F., Teoría y Realidad Constitucional, núm. 25, Madrid.

RELLSTAB, U. (2001), «Transversal Study Cultural Policy and Cultural Diversity. National report Switzerland», Council of Europe, Strasbourg.

REY MARTÍNEZ, F. (2010), «El Problema Constitucional del Hijab», Revista General de Derecho Constitucional, 10.

RUIZ VIEYTEZ, J. (2013), «Democracia Directa y Religión: Problemas Derivados de la Decisión Suiza de Prohibir los Minaretes», Revista de Derecho Político, núm. 87.

SÁNCHEZ GONZÁLEZ, S. (1992), La Libertad de Expresión, Madrid, Marcial Pons.

SOLANO, M. (2003), Libertad de expresión en las Américas. Los cinco primeros informes de la Relatoría para la Libertad de Expresión, Instituto Interamericano de Derechos Humanos, San José.

STONE, R. (2012), Textbook on Civil Liberties and Human Rights, Oxford University Press.

VARÓN MEJÍA, A. (2010), «Orden público internacional y normas «ius cogens»: una perspectiva desde la comisión de derecho internacional y la convebnción de Viena de 1969», Diálogos de saberes: investigaciones y ciencias sociales, núm. 32. WEST, C. (2012), «Words That Silence? Freedom of Expression and Racist Hate Speech» en MAITRA, I. y McGOWAN, M., Oxford University Press. 
Title:

\section{HATE SPEECH AND RELIGIOUS TOLERANCE IN THE SWISS PARTICIPATORY DEMOCRACY.}

\section{Summary:}

1. Introduction. 2. Swiss constitutional premises and acceptance of international law. 3. Extreme political discourse: «hate speech». 4. Hate speech and anti-discrimination legislation in Switzerland. 5. Conclusions.

\section{Resumen:}

El 21 de diciembre de 1965, la Asamblea General de las Naciones Unidas emitía una señal de alarma ante las constantes manifestaciones de discriminación racial y por las políticas gubernamentales basadas en la superioridad y el odio racial. De aquella asamblea surgió un Convenio por el que se condenaba toda la propaganda y toda organización basada en la superioridad de una raza o grupo de personas de un determinado color u origen étnico; declarando ilegales las actividades organizadas de propaganda, y cualquiera que promoviese la discriminación racial e incitara a ella. Un año después, el 16 de diciembre de 1966 , la misma asamblea anunciaba otro pacto internacional por el que se prohibía toda propaganda en favor de la guerra, toda apología del odio nacional, racial o religioso que incitara a la discriminación, la hostilidad o la violencia. Ambos fueron aceptados y ratificados ampliamente en el panorama internacional, sin embargo, pasadas más de cuatro décadas continuamos entre cenit y nadir.

Desde entonces, el panorama helvético no ha sido ajeno a las manifestaciones de superioridad y odio. Su constatable histórica hospitalidad se ha visto doblegada en los últimos años; facilitada por un lado, por el escepticismo helvético en la aceptación del Derecho Internacional, y, por otro más influyente, ante la escalada de partidos políticos ultra conservadores, que a través de sus discursos y propaganda han logrado en numerosas ocasiones doblegar la voluntad del Derecho Internacional de los Derechos Humanos y el propio nacional en contra de las minorías que consideran que desafían los valores histórico-culturales helvéticos.

\section{Abstract:}

On December 21 of 1965, the General Assembly of the United Nations sent out an alarm signal because of the constant manifestations of racial discrimination and because of the governmental policies 
based on racial superiority or hatred. Result of that assembly was an agreement which condemned all propaganda and all organisations based on the superiority of one race or groups of persons of a specific skin colour or ethnic origin. It declared as illegal all organised propaganda activities, and anyone that would promote the racial discrimination and incite to it. One year later, on December 16 of 1966, the same assembly announced another international agreement by which it prohibited any propaganda for war, any advocacy of national, racial or religious hatred that incites discrimination, hostility or violence. Both were widely accepted and internationally ratified. However, more than four decades later, we still stand between Zenith and Nadir.

Also Switzerland was not immune to these manifestations of superiority and hatred. Its famous historical hospitality has been affected in recent years; on one hand, due to Swiss skepticism in accepting international law, and on the other, because of the rise of ultra conservative political parties, which, through their speeches and propaganda, have managed in numerous occasions, to incite against minorities by breaking the international law of human rights and the national law. Minorities, who they consider threatening to the Swiss cultural and historical values.

\section{Palabras Clave:}

Democracia participativa, ius cogens, discurso de odio, propaganda, velo islámico.

\section{Key Words:}

Participative democracy, ius cogens, hate speech, propaganda, Islamic hijab. 
